\title{
Satellite monitoring of forest fires and associated smoke plumes occurring in Korea
}

\author{
Y. S. Chung • H. S. Kim
}

Received: 2 August 2007 / Accepted: 13 June 2008 / Published online: 19 July 2008

(C) The Author(s) 2008. This article is published with open access at Springerlink.com

\begin{abstract}
Operational research was carried out on satellite detection of forest fires and associated smoke plumes occurring in the Korean Peninsula. Forest fire data and satellite images obtained from 2004 to 2007 were examined. It was observed that at least three forest-fire episodes were caused by atmospheric lightning, while all other cases were recorded as anthropogenic causes, according to data gathered from the Korean meteorological and forestry services. For two episodes, there were 60 120 forest fires in North and South Korea, observations based on hotspots analysis. Smoke plumes transported over 1,200 km were observed. There was discussion of the role played by the emission of heated air and greenhouse gases in general warming and climate change in regional and global atmospheres, e.g., Arctic ice melting. With global warming, ice over the Arctic Ocean is melting significantly in summer (Chung and Le, Int J Remote Sens 25(2):front cover and 291-296, 2004). The suppression of forest fires caused by human activities is suggested to improve the atmospheric environment and to prevent climate change in the near future.
\end{abstract}

Keywords Forest fire and smoke plumes · Satellite detection of smoke plumes · Emission from forest fires $\cdot$ Forest fire climatology $\cdot$ Korean Peninsula

\section{Introduction}

Forest fires and resulting smoke increase regional and global warming and climate change (Chung et al. 2004).

Y. S. Chung $(\bowtie) \cdot$ H. S. Kim

Korea Centre for Atmospheric Environment Research,

Khangnae, Cheongwon 363-891, Korea

e-mail: kccar1@kornet.net
Climate changes are presently occurring in many parts of the world. Forest fires are occurring in all five continents, initiated by natural and anthropogenic causes including atmospheric lightning and irresponsible human activities. In Canada, lightning is a cause of wild fires, and these account for about half of all burned areas ( $\sim 2$ million hectares) per year (Chung 1984; Stocks et al. 2003). In populous countries, human activities cause more forest fires than atmospheric lightning. Likewise, the generation of a forest fire by atmospheric lightning is not common in Korea (Chung 2003). The size of Korea is $220,000 \mathrm{~km}^{2}$, and South Korea $\left(99,000 \mathrm{~km}^{2}\right)$ alone produces on average over 420 forest fires per year.

Forest fires emit heat and atmospheric constituents including $\mathrm{CO}_{2}, \mathrm{CO}$, aerosols (dust), hydrocarbons ( $\mathrm{HC}$ ), shoots, and water vapor (Chung 1984). Greenhouse gases including $\mathrm{CO}_{2}, \mathrm{CH}_{4}, \mathrm{~N}_{2} \mathrm{O}, \mathrm{CO}$, and emitted heat from forest fires are positive agents for global warming. When a forest area is destroyed, it also provides an opportunity for radiative heating of the atmosphere, and the photosynthetic function of a forest comes to a halt, contributing to more atmospheric warming.

Resulting heat and smoke from forest fires generate atmospheric impacts including visibility reduction and radiant heating of the lower atmosphere at local, regional, and global scales. Smoke plumes and greenhouse gases travel for long distances over land and oceans, and they also play a role in global warming. For example, the Arctic air is warmed up and significant ice thaw in the Arctic Ocean is observed in summer (Chung and Le 2004).

In general, wild fires destroy vegetation including trees and weeds, but they also destroy houses and create casualties. Toxic air pollutants, like $\mathrm{CO}$ and some toxic $\mathrm{HC}$, cause respiratory problems and are very hazardous to residents living near forest fires. 
In Korea, large wild fires occurred on 10 April 2000 (Chung 2003). During the investigation to find the cause of the fires, many people faced criminal charges from the public prosecutor's office. We swiftly announced that the wild fires in both North and South Korea were caused by atmospheric lightning. The prosecutors respected our research results, and a dozen innocent citizens falsely accused were immediately released. Clearly, scientific research provides knowledge but also serves to guard the interests of justice.

The purpose of the present study is to present the results of daily monitoring of forest fires in Korea by National Oceanic and Atmospheric Administration (NOAA) satellites. Satellites have been used for many years in the detection of forest fires (Kucera et al. 2005; Matson and Stephens 1987; Lee and Tag 1990; Li et al. 2000). The present study includes a large amount of forest-fire data obtained from 2004 to 2007. Meteorological and forest-fire data from the Korea Forest Service (KFS) and Korea Meteorological Administration (KMA) were utilized. Discussion is made on finding the impact of forest fires caused by atmospheric lightning. Emission data of annual forest fires (e.g., Amiro et al. 2001; Chung 1984) and impact on air quality are also included in "Discussions and conclusions".

\section{Forest-fire climatology}

Forest fire data were obtained from the KFS. Statistical analysis was carried out with the quality control of all data. Forest fires in general occur throughout the year. In Korea, numerous fires occur mostly in April and March, totaling 1,506 and 1,458, respectively. Fewer fires occur in February, May, January, and December, as shown in Fig. 1.

Table 1 includes the annual number of forest fires occurring in South Korea from 1990 to 2006. For a period of 17 years, the annual average number of forest fires was 424 , with an annual average burnt area of 2,906 ha. The smallest number of fires occurred in 1990 with 71 cases,
Table 1 Annual number of forest fires and the burned area from 1990 2006 (data obtained from the Korea Forest Service)

\begin{tabular}{lrr}
\hline Year & Fires & Area (ha) \\
\hline 1990 & 71 & 175 \\
1991 & 139 & 429 \\
1992 & 180 & 640 \\
1993 & 278 & 1,752 \\
1994 & 433 & 781 \\
1995 & 630 & 1,013 \\
1996 & 527 & 5,368 \\
1997 & 524 & 2,330 \\
1998 & 265 & 1,014 \\
1999 & 315 & 473 \\
2000 & 729 & 25,953 \\
2001 & 785 & 963 \\
2002 & 599 & 4,467 \\
2003 & 271 & 133 \\
2004 & 544 & 1,588 \\
2005 & 516 & 2,067 \\
2006 & 405 & 254 \\
Average & 424 & 2,906 \\
\hline
\end{tabular}

and the largest number of forest fires was recorded at 785 in 2001. The area burnt in 2000 was the largest at 25,953 ha, and large wild fires in the east coastal hills and mountains caused by atmospheric lightning destroyed 20,752 ha on 10 and 11 April (Chung 2003).

In South Korea, during the period 1997 2006, about $73.2 \%$ of all forest fires $(4,953)$ occurred between February and April, and $96.8 \%$ of the total area was burned in those 3 months. In July and August, the average number of forest fires was only five and four, respectively, and the areas burnt came to less than 1 ha. In the rainy summer season of June, July, August, and September, the occurrence of forest fires was at a minimum and growth in vegetation was active.

Large fires occurred mainly in April with an average burnt area of $22.4 \mathrm{ha}$, while the average burnt areas in February and March were 1.6 and 2.5 ha, respectively. The
Fig. 1 Monthly number of forest fires occurring from 1997 to 2006 (data obtained from the Korea Forest Service)

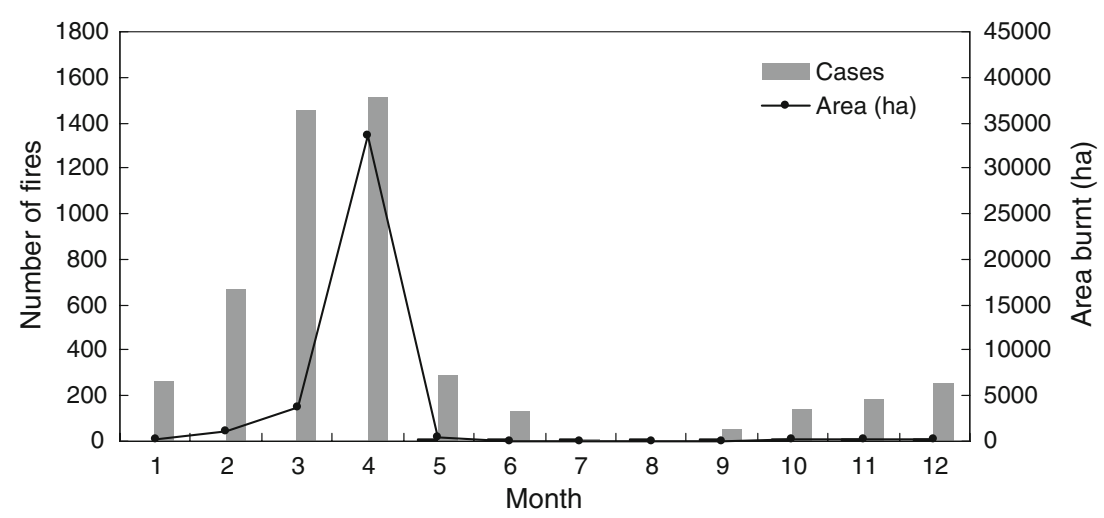


forest fires in Korea were generally small in size compared with wild fires occurring in Canada, the USA, and Russia.

According to our examination of the cause of fires, wild fires caused by atmospheric lightning are relatively uncommon (less than 10\%) in Korea (Chung 2003). In Canada, however, forest fires owing to atmospheric lightning are about equal to $(\sim 50 \%)$ anthropogenic forest-fire occurrences (Chung 1984). In South Korea, the causes of forest fires have been divided into categories: careless hikers $43.4 \%$; agricultural burning $17.3 \%$; trash burning $8.1 \%$; cigarettes $9.1 \%$; tomb visitors $6.3 \%$; children $2.8 \%$; and miscellaneous $13.0 \%$.

Atmospheric lightning is included in miscellaneous, and, for example, there were five cases of fires caused by lightning on 4 November 2006. Incidentally, several airquality monitors of the present research centre were burnt by lightning strikes on the same day.

\section{Observations}

NOAA satellite data are received routinely at the present research centre, and environmental analysis of real-time data including forest fires detection is carried out.

The advanced very high resolution radiometer (AVHRR) is a radiation-detection imager that can be used for remotely determining smoke plumes and the surface of the Earth. The latest instrument version is AVHRR/3, with six channels, first carried on NOAA-15 launched in May 1998. Table 2 shows the characteristics of six channels. We have been using channels 1,2 , and 4 for the false-colour composite analysis to detect forest-fire smoke plumes, and channel 3B is used for detecting hotspots produced by forest fires.

A cold front was passing through Peongyang, North Korea, at 21:00 LST, 13 April 2004, and this is suggested to have triggered atmospheric lightning to cause many

Table 2 The characteristics of six channels used in the advanced very high resolution radiometer (AVHRR) of NOAA satellites

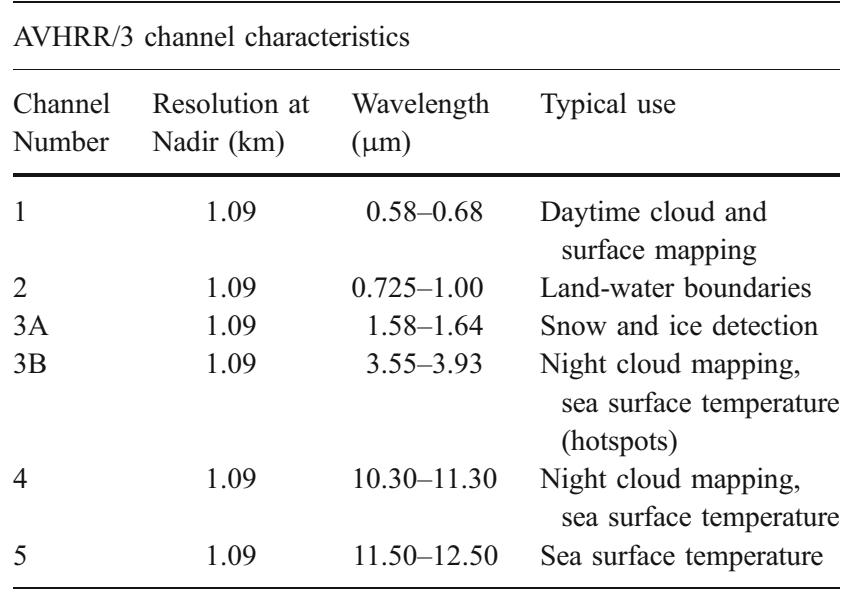

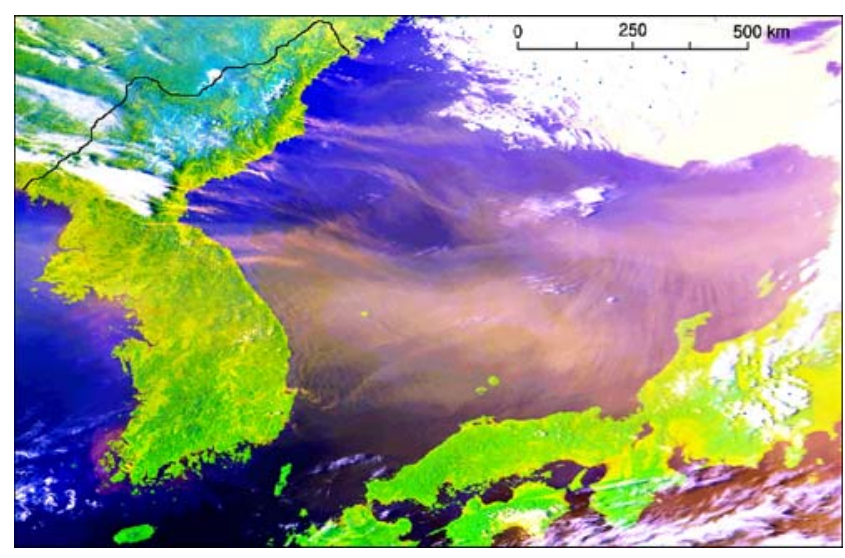

Fig. 2 A satellite image showing giant smoke plumes from forest fires in Korea at 16:52 LST, 16 April 2004 (NOAA-12; channels 1, 2, and 4)

forest fires (Chung and Le 1984) in eastern North Korea. The meteorological front produced light rain, while the föhn effect generated the warm dry air on the lee side of the N-S-oriented Korea Mountains in the Peninsula.

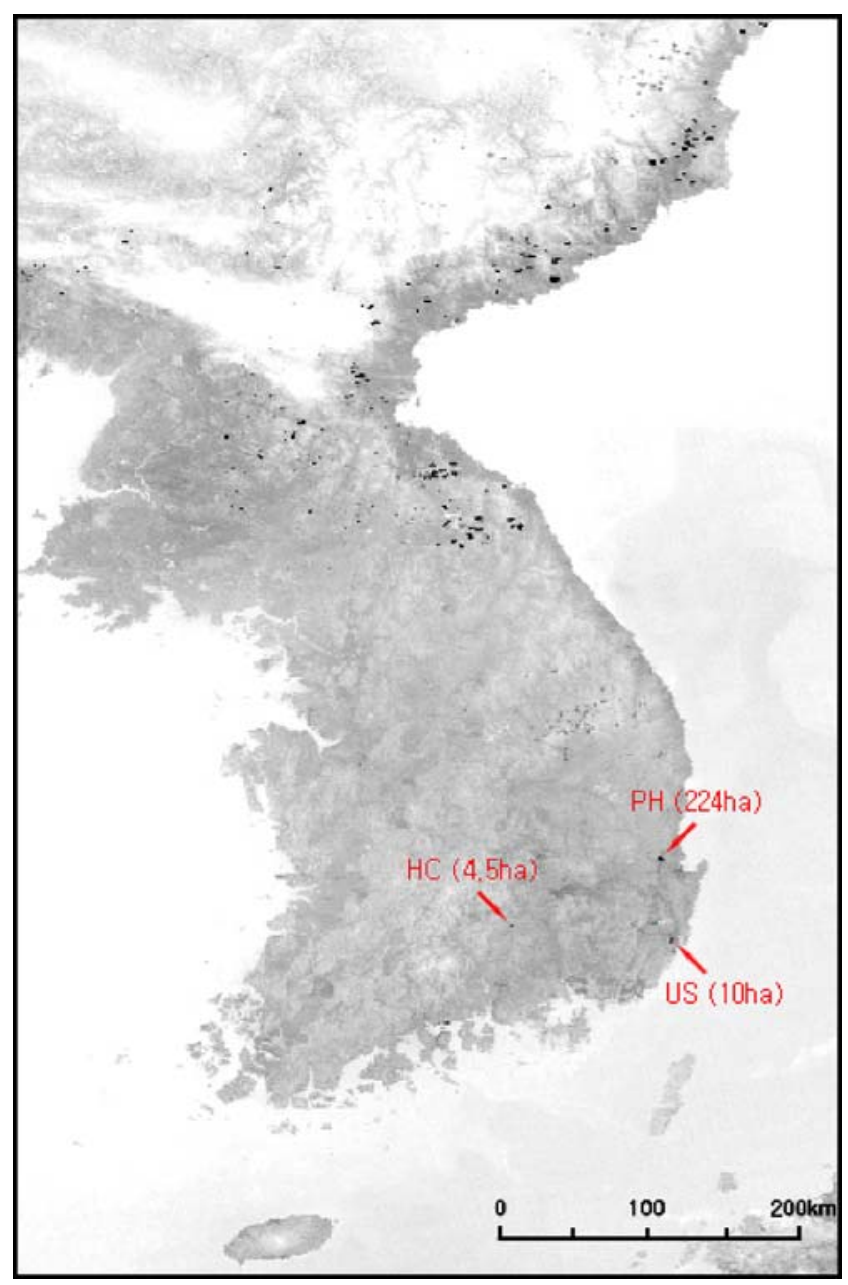

Fig. 3 Hotspots analysis at 16:52 LST, 16 April 2004 (NOAA-12; channel 3) 
Table 3 Number of pixels counted for forest fires occurring at 16:52 LST, 16 April 2004 (NOAA-12)

\begin{tabular}{|c|c|c|c|c|c|c|c|c|}
\hline \multirow[t]{2}{*}{ Lat. ${ }^{\circ} \mathrm{E}$} & \multicolumn{8}{|l|}{ Lon. ${ }^{\circ} \mathrm{E}$} \\
\hline & $123 \sim 124$ & $124 \sim 125$ & $125 \sim 126$ & $126 \sim 127$ & $127 \sim 128$ & $128 \sim 129$ & $129 \sim 130$ & $130 \sim 131$ \\
\hline $43 \sim 44$ & 0 & 0 & 0 & 0 & 0 & 0 & 0 & 0 \\
\hline $42 \sim 43$ & 0 & 0 & 0 & 0 & 0 & 0 & 6 & 10 \\
\hline $41 \sim 42$ & 0 & 0 & 0 & 0 & 0 & 0 & 46 & 0 \\
\hline $40 \sim 41$ & 0 & 5 & 6 & 3 & 12 & 55 & 9 & 0 \\
\hline 39 40 & 0 & 0 & 0 & 18 & 43 & 0 & 0 & 0 \\
\hline 38 39 & 0 & 0 & 0 & 8 & 56 & 19 & 0 & 0 \\
\hline $37 \sim 38$ & 0 & 0 & 0 & 0 & 0 & 0 & 0 & 0 \\
\hline $36 \sim 37$ & 0 & 0 & 0 & 0 & 0 & 0 & 4 & 0 \\
\hline $35 \sim 36$ & 0 & 0 & 0 & 0 & 0 & 0 & 1 & 0 \\
\hline $34 \sim 35$ & 0 & 0 & 0 & 0 & 0 & 0 & 0 & 0 \\
\hline
\end{tabular}

On the satellite imagery, the initial detection of forestfire smoke was made at 03:17 LST, 15 April 2004. As shown in Fig. 2, forest fires were burning, and the resulting smoke plumes were flowing out of the east coast of North and South Korea at 16:52 LST, 16 April. The method of forest fire detection is discussed in Chung and Le (1984).

Numerous hotspots of fires were clearly visible in the west side of the eastern coast-line (Fig. 3), and plumes were also visible over the sea (Fig. 2). Those plumes were transported over the Korea East Sea and onward to NW Japan. The distance from the forest fires to Akita in Japan exceeded $1,025 \mathrm{~km}$. The number of forest fires in North Korea was over 60 at 04:50 LST, 16 April. The exact number of fires could not, however, be confirmed owing to the lack of scientific exchange with North Korea. Eight fires in South Korea were under 3 ha in size, while four fires were burning in Haapcheon (HC) at 4.5 ha, Ulsaan (US) 10 ha, and Pohaang (PH) at 224 ha. Figure 3 enables us to estimate the fire areas in North Korea. In contrast, there were 12 forest fires in South Korea on 16 April, according to the KFS.

Although the size of 1 pixel on channel 3 of NOAA satellites is 121 ha $(1.09 \times 1.09 \mathrm{~km})$, we were able to detect a fire as small as 2 ha in size. The actual size of the area burnt was confirmed with the data obtained from the KFS.

Fig. 4 A meteorological map at 21:00 LST, 30 April 2005 (of KMA)

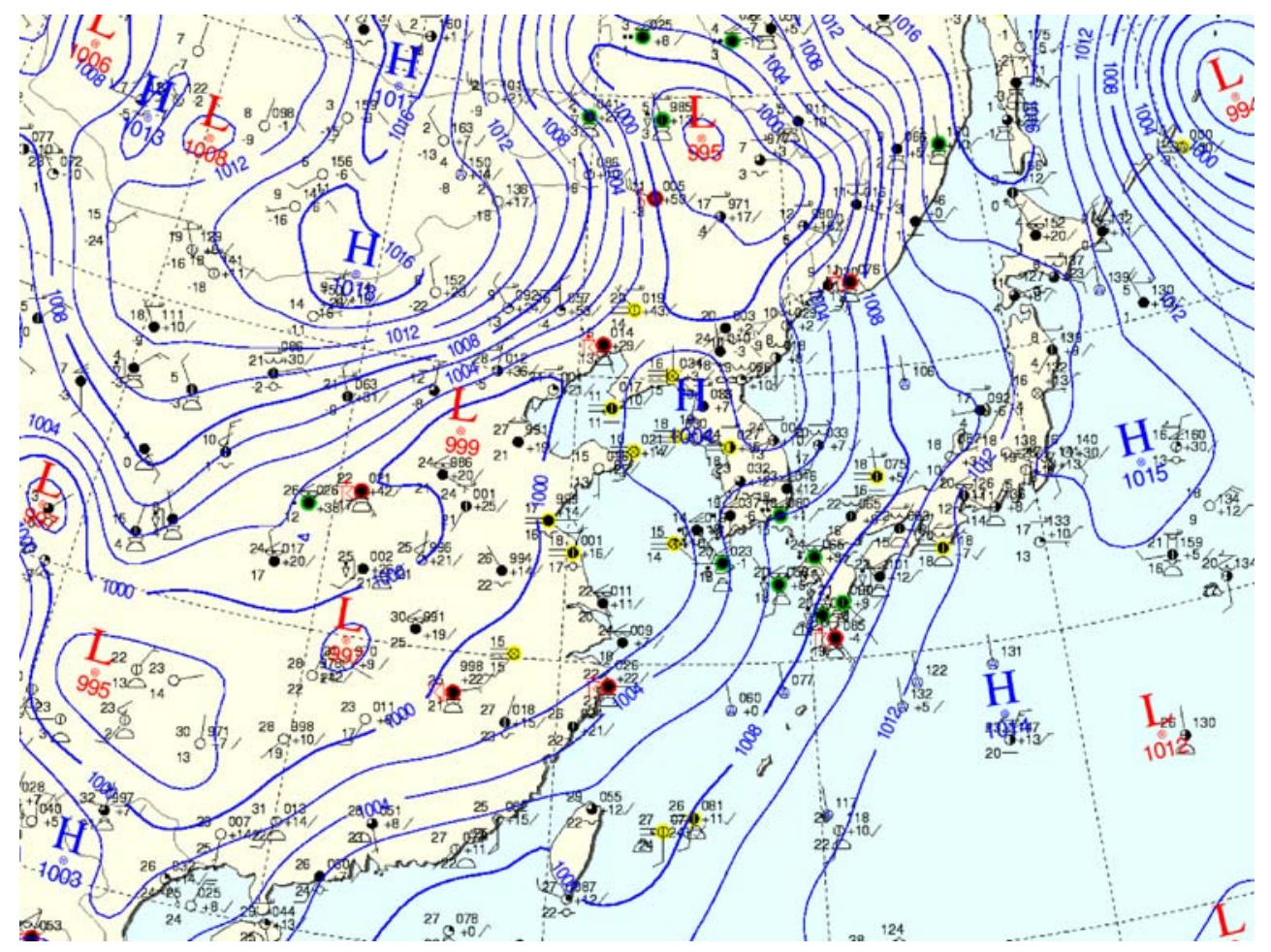


A forest fire of 2 ha generates high air temperature in an area as large as 121 ha. The hot fire spot appears as a warm pixel in the channel 3 of satellite images. The air surrounding a fire area is heated, and it can be transported continuously to a distance of $1.5 \sim 3.6 \mathrm{~km}$ in $1 \mathrm{~h}$ with weak winds of $0.5 \sim 1 \mathrm{~ms}^{-1}$; this can create approximately one to two warm pixels.

Table 3 shows the number of hotspot pixels within each degree of latitude and longitude over the Korean Peninsula in the present case of 16 April 2004 (at 16:52 LST; NOAA12). Comparing Figs. 2 and 3 with Table 3, we observe that numerous forest fires were seen in North Korea, particularly to the north of $38^{\circ} \mathrm{N}$ and to the east of $127^{\circ} \mathrm{E}$. In this case, the number of hot pixels over the North Korean fire areas was 296 in total. As mentioned already, forest fires in North Korea were believed to be caused by atmospheric lightning, while the cause of South Korean fires was recorded as "anthropogenic" by the KFS.
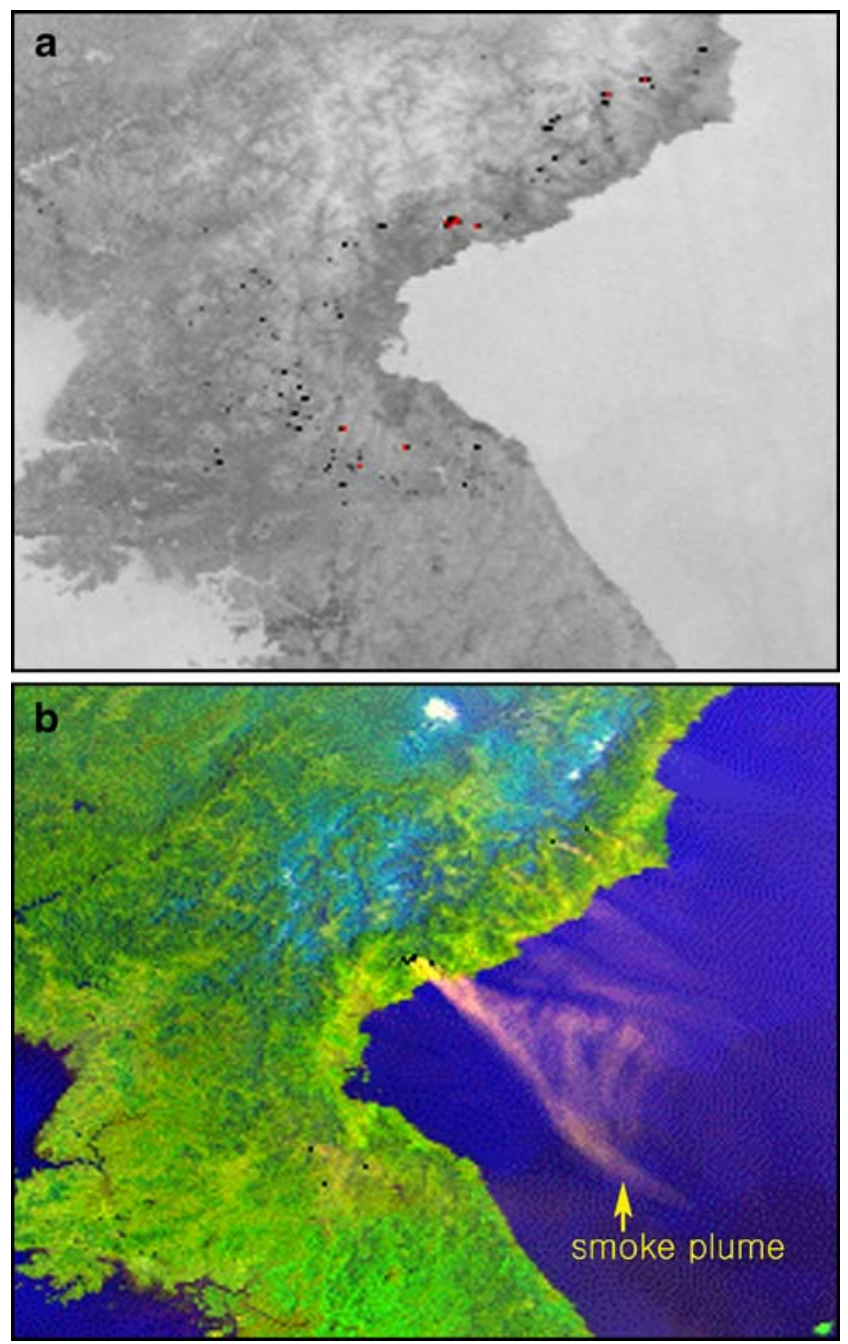

Fig. 5 a Hotspots analysis at 17:18 LST, 2 May 2005 (NOAA-12; channel 3); b a satellite image showing giant plumes at the above time (NOAA-12; channels 1, 2, and 4)
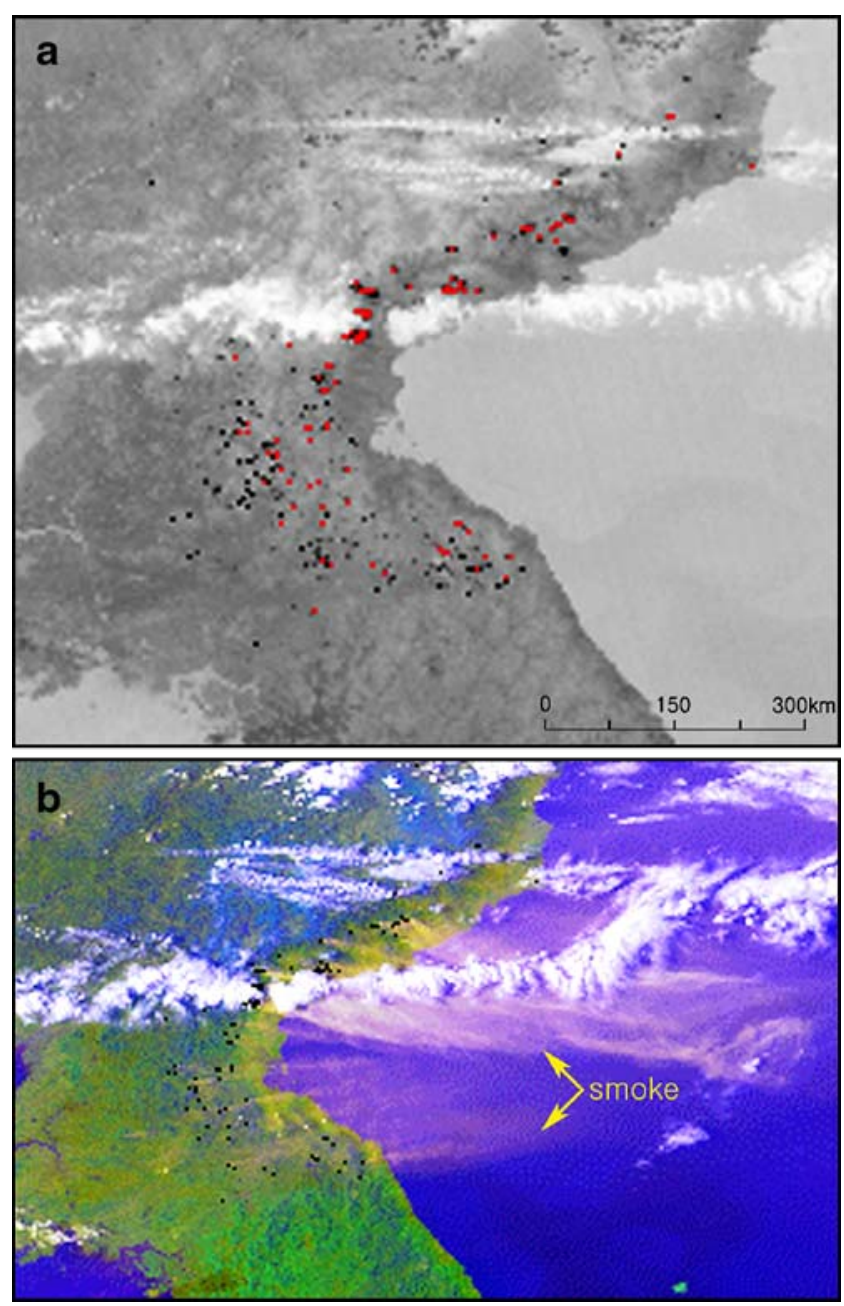

Fig. 6 a Hotspots analysis at 16:53 LST, 3 May 2005 (NOAA-12; channel 3); b a satellite image showing extensive smoke at the same time (NOAA-12; channels 1, 2, and 4)

On 24 April 2004, there were over a dozen forest fires in North Korea. The cause of the fires was not known, but they seemed to arise from agricultural activity and fire mishandling. From daily analysis, many forest fires and associated smoke plumes occurring in eastern North Korea were also detected during the period 4 8 April 2005. There were at least 50 forest fires in North Korea, and meteorological maps do not suggest any occurrence of thunderstorm and lightning: The cause of these fires was unknown.

The present case is to discuss the effect of atmospheric lighting to cause many forest fires in North Korea. Figure 4 shows a meteorological map (KMA) at 21:00 LST, 30 April 2005. It shows that a cold front was passing through North Korea during the day. An anticyclone situated over eastern Mongolia was producing dry dusty air that pushed the cold front eastward. Moreover, a dust storm from the Gobi Desert was also associated with the west side of the cold front, and this synoptic situation did produce a dry cold front and atmospheric lightning. There were two reports of 


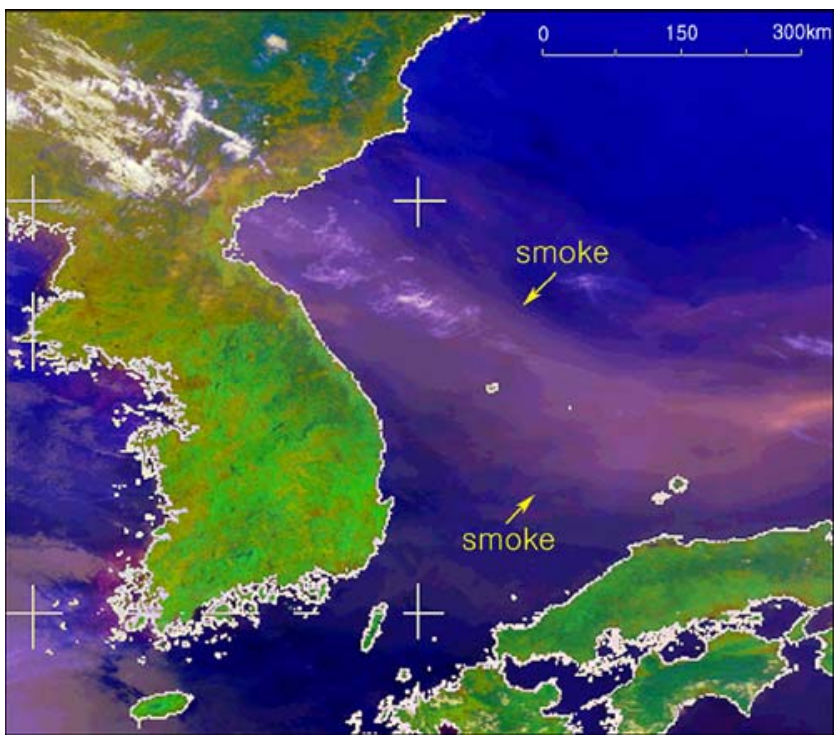

Fig. 7 A satellite image showing giant smoke plumes formed in the Korea East Sea at 11:31 LST, 4 May 2005 (NOAA-17, channels 1, 2, and 4)

atmospheric lightning on the surface map, one over Vladivostok, Russia, and another one over the southern part of NE China. These conditions were ideal for the production of dry lightning over North Korea, especially on the east side of the Korea Mountains.

There were many forest fires happening in North Korea on 2 May 2005. The number of wild fires was increasing on

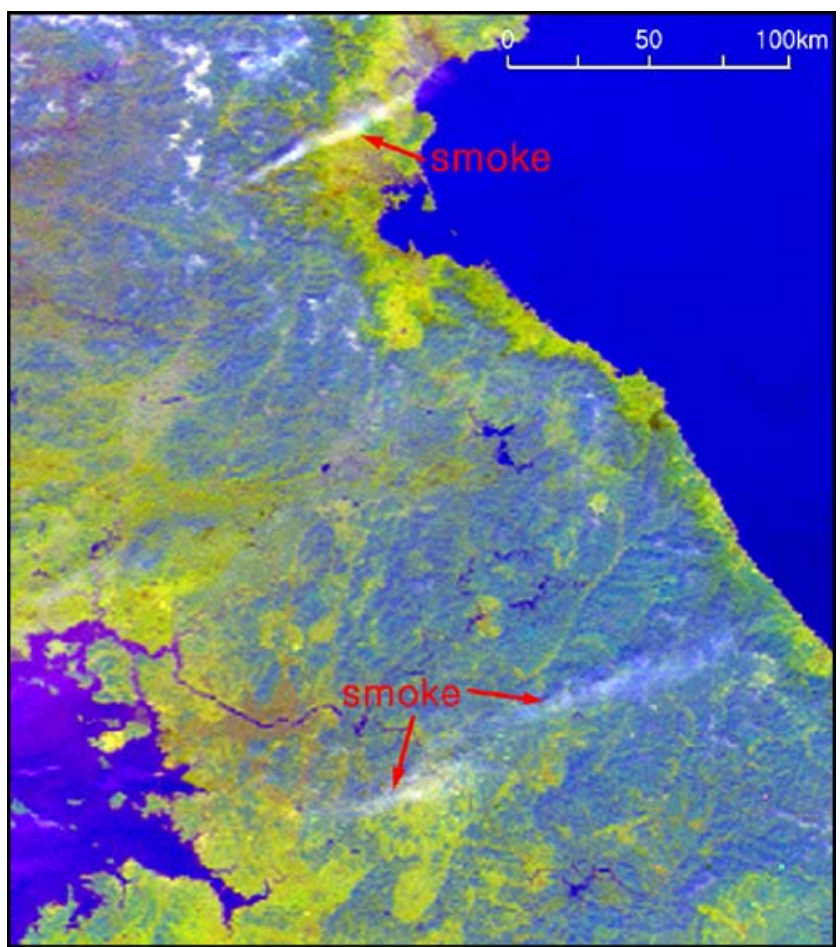

Fig. 8 A satellite image showing smoke plumes over the ground at 11:10 LST, 24 March 2006 (NOAA-17; channels 1, 2, and 4) the lee side of the Korea Mountains, and at 17:18 LST, 2 May, the number of forest fires was about 60 . In general, the warm and dry air with föhn occurs in the lee side of mountains. Meanwhile, the largest smoke plume from the north of Hongwon near Haamnam was spewing out to the Korea East Sea (Fig. 5).

Figure 6 is a satellite image at 16:53 LST, 3 May 2005, and Fig. 6a shows hotspot analysis, while Fig. 6b shows large smoke plumes coming out of hotspots in North Korea. The red spot in Fig. 6a represents an area of violent forest fires emitting the hotter air, while the black spot shows an area of the lesser heated air. There were over 140 wild fires according to the hotspots. Most of the East Sea of North Korea was covered by smoke plumes from forest fires. According to Fig. 7, a giant plume was formed from many individual fires and was reaching out to Japan. The width of the giant plume was over $400 \mathrm{~km}$, and its length exceeded
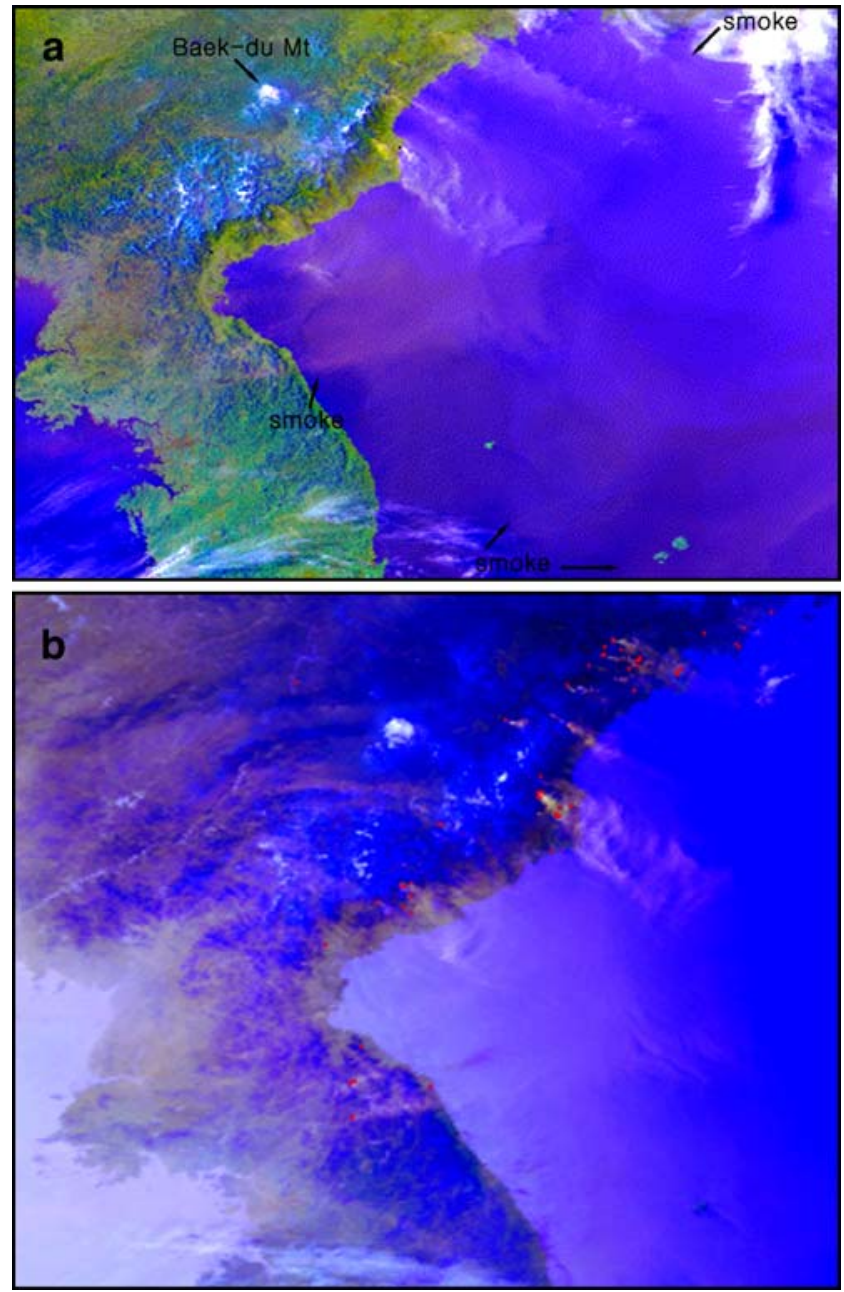

Fig. 9 a A satellite image showing extensive smoke plumes flowing out to sea (NOAA-15, 17:41 LST, 29 April 2007; channels 1, 2 and 4); b hotspots analysis at 16:33 LST, 29 April 2007 (NOAA-12, channels 1, 2, and 4) 
$1,350 \mathrm{~km}$. Meanwhile, according to satellite imagery, a large cloud system moved in on 5 May, and rainfall occurred over the region of wild forest fires. As a result, most forest fires died out with the spread of the rain shower. Furthermore, Figs. 3, 5, and 6 show that many forest fire occurred in eastern Korea. The warm and dry air conditions prevail in the east side of the Korea Mountains with föhn effect to cause forest-fire weather.

The KFS reported 31 forest fires occurring on 24 and 25 March 2006, but most of them were under 1 2 ha in size. Figure 8 shows smoke plume occurring on the land surface on 24 March 2006. With our improvement in satellite analysis, the detection of smoke plume was also possible even if the plume was over land (Chung and Le 1984). Owing to higher albedo and reflectivity over the land surface, the smoke detection over the land was difficult. However, new information on satellite analysis is useful for smoke detection.

On 29 April 2007, there were approximately 70 hotspots over the Korean Peninsula, including eight forest fires near the Vladivostok area of Far Eastern Russia. In particular, the forest areas of 2 ha at Hamyang and of 3.5 ha at Seosan in South Korea were burning. By refining fire detection techniques perfected in South Korea, we can estimate the number of forest fires in North Korea and their sizes from the same image. Our results will be confirmed since we have now initiated contact with North Korea for scientific exchange.

The wide spreading of smoke plumes coming out from forest fires to the Korea East Sea is also shown in Fig. 9a. It clearly depicts the widespread smoke plumes over the sea from the Korean Peninsula. Incidentally, the image also detects the snow-capped mountains, including Baek-du Mountain, which is $2,744 \mathrm{~m}$ above sea level. Figure $9 \mathrm{~b}$ is a composite image obtained with channels 1,2 , and 4 for the case of 17:41 LST, 29 April 2007. In particular, the image detects hotspots and associated smoke plumes over both land and sea. According to our examination of weather maps and upper-air data, we conclude that atmospheric lightning was not a cause in the present episode.

There were also numerous forest fires and associated smoke plumes on 4 May 2007. The satellite image obtained at 17:22 LST clearly showed several smoke plumes drifting out from forest fires in North Korea to the sea.

\section{Discussions and conclusions}

Annually, forests of about 3,000 ha are destroyed by forest fires, and this equates to 41,000 tons of firewood. A tree consists of approximately $40 \%$ water, and the remainder is mainly carbon. When it is burnt, $\mathrm{CO}_{2}, \mathrm{HC}$, dust, and water vapor are created. Using stoichiometric calculations, we estimate the total amount of emissions, including $\mathrm{CO}_{2}, \mathrm{HC}$, and dust, from forest fires in South Korea at approximately 149,000 tons per year.

Fires greater than 2 ha in size were detectable by NOAA satellite analysis. This was done by the analysis of hotspots and associated smokes. In Korea, according to ground reports by KFS, large wild fires caused by atmospheric lightning were found to occur infrequently, while fore climatology shows that the majority of small fires $(\sim 90 \%)$ were caused by people. In North Korea, for an episode case, there were $60 \sim 120$ forest fires, and they were caused by both lightning and by human activities. Meanwhile, the present monitoring of forest fires is an ongoing operation, and numerous fires detected routinely both over North and South Korea have been shown several times in the media, including major newspapers and the TV network in Seoul.

With increases in population and industrial activities, the number of forest fires also increased in general. In recent years, however, a decreasing trend has been observed in the frequency of forest fires in South Korea. This is attributed to improved quality of forest-fire suppression with a fleet of over 20 water bombers.

The satellite detection of smoke plumes not only provides the geographical distribution of forest fires, but it also quantifies long-distance transport of smoke emission from forest fires. Daily (routine) satellite monitoring is a useful technique for detecting wild fires in remote areas. Even without the exchange of forest fire information, we were still able to monitor forest fires in a different country. The number of forest fires should be reduced and controlled in order to reduce regional and global greenhouse gases and air pollutants. This in turn will help us reduce climate change and respiratory problems as well.

Acknowledgment The science subvention provided by Cater (20063103 ) and the assistance given by Mr. Park K. H. are appreciated.

Open Access This article is distributed under the terms of the Creative Commons Attribution Noncommercial License which permits any noncommercial use, distribution, and reproduction in any medium, provided the original author(s) and source are credited.

\section{References}

Amiro BD, Stokes BJ, Alexander ME, Flannigan MD, Wotton BM (2001) Fire, climate change, carbon and fuel management in the Canadian boreal forest. Int $\mathrm{J}$ Wildland Fire 10: 405-413

Chung YS (1984) On the forest fires and the analysis of air quality data and atmospheric ozone. Atmos Environ 18:2153-2152

Chung YS (2003) Satellite detection of forest fires in Korea and associated smoke plumes. Int J Remote Sens 24(1):front cover and $1-7$ 
Chung YS, Le HV (1984) Detection of forest-fire smoke plumes by satellite imagery. Atmos Environ 18:2143-2151

Chung YS, Le HV (2004) Satellite detection of ice melt over the Arctic Ocean. Int J Remote Sens 25(2):front cover and 291-296

Chung YS, Yoon MB, Kim HS (2004) On climate variations and change observed in south Korea. Clim Change 66:151-161

Kucera J, Yasuoka Y, Dye DG (2005) Creating a forest fire data base for the Far East Asia using NOAA/AVHRR observation. Int J Remote Sens 26-11:2423-2440
Lee TF, Tag PM (1990) Improved detection of hotspots using the AVHRR 3.7- $\mu$ m channel. Bull Am Meteorol Soc 71:1722-1730

Li Z, Nadon S, Cihlar AR (2000) Satellite-based detection of Canadian boreal forest fires: development and application of the algorithm. Int J Remote Sens 21:3057-3069

Matson M, Stephens G (1987) Fire detection using data from the NOAA-N satellite. Int J Remote Sens 8:961-970

Stocks BJ et al (2003) Large forest fires in Canada, 1959-1997. J Geophys Res 108(D1):8149-8164 